\title{
What has sight got to do with it? On the representation of concepts in blind children's drawings
}

ABSTRACT. The paper analyses sample drawings produced by blind children. The focus will be put on the representation of concepts. Major findings gathered in the discussion section show that sight plays complementary rather than primary role in the process of conceptual development, which supports other research in the field of blindness studies conducted so far.

KEYWORDS: drawing, blind child, conceptual development.

\section{CONCEPT DEVELOPMENT IN A BLIND CHILD. FROM DELAY TO INDIVIDUAL DIFFERENCES APPROACH}

The major manifestation of each child's development is the longitudinal and multi-faceted process of ascribing meaning to tangible and intangible items that exist in the surrounding world. Among an extensive number of definitions, a concept is considered, inter alia, to be a "structured mental representation with sub-propositional content" (Margolis \& Laurence 2006: 1812) or the "idea which is conceived through abstraction and through which objects or states of affairs are classified on the basis of particular characteristics and/or relations" (Bussmann et al. 1996: 815). The senses that a human being engages in the process of conceptual development can be put in a hierarchy of less and more valued ones; obviously vision is the most cherished of all the senses in most communities and treated as the most careful and elaborate sense modality. For this particular reason, vision 
delivers information in a very quick and painstaking fashion revealing minute details of objects such as shape, gloss, colour, contour to mention but a few. Touch would probably trail in second position. Nevertheless, touch, contrary to sight, requires much more time to trace the characteristics of a certain thing, not to mention that there are many phenomena that remain beyond the reach of touch. So accordingly, a blind child is disadvantaged when confronted with the task of learning the meanings of concepts (e.g. Majewski 1983; McLinden, McCall 2002). Landau and Gleitman thus state:"To the extent that blind children's extralinguistic contexts for the words and sentences they hear differ from those of sighted children, one might expect their language learning differs as well" (Landau \& Gleitman 1985: 2).

The development of conceptual knowledge in a blind child was analysed from various angles and provoked incongruous views starting from the earliest accounts of impoverished and delayed cognitive and language development (Cutsforth 1932) to the present individual differences approach according to which a blind child develops concepts in the way similar to his or her sighted counterparts, albeit in a slower pace (e.g. Landau 1983; Perez-Pereira, Conti-Ramsden 1999; Dunlea 1989). The first studies on the blind child's development focused on the limitations arising out of the lack of sight. This was expanded by Cutsforth (1932) in his theory of verbalism or verbal unreality of words in the light of which the language blind people use is semantically empty as not being marked by any manifestation of personal, direct experience but rather originates from imitation of the sighted people's utterances.

The scholars such as Dokecki (1966), DeMott (1972), Landau (1983), Millar (1994), Perez-Pereira and Conti-Ramsden (1999), Rosel et al. (2005) amongst others who support their ideas by a vast array of tests such as association tests, matching tests, vocabulary tests or longitudinal observations of a child's development documented by diaries and parents' reports hold that lexical items in blind children's mental encyclopaedias bear similar meanings to sighted people's lexical items, and there is no reason, whatsoever, to propound that blind children's language and cognitive skills are underdeveloped in any way. Gleitman (1990) emphasises the role of the context. According to her syntactic bootstrapping theory, children infer the meanings of words from syntactic cues. In other words, children figure out what a particular word means by analysing other adjacent words in a sentence.

Special attention was attached to the understating of purely visual or vision-based concepts. It was found that blind children properly understand colours, can distinguish various colours, are able to match colour to its representative object (Landau, Gleitman 1985), can differentiate warm and cold 
colours (Perez-Pereira, Conti-Ramsden 1999), compare colours to sounds or emotions (Sękowska 1974; Majewski 1983) or form expressions with colours (Millar 1994). Much insight into the study of blind children was given by Landau and Gleitman (1985). Very interesting data was gathered as to the understanding of the verb 'look' that a blind child associated with 'touch'. Touching meant a direct contact with the object, whereas looking meant exploring or apprehending. Sighted children, in contrast, understood looking as a purely visual activity and touch as contact. This can be explained by the fact that sighted and blind children apply different dominant sense modality, which is visual for sighted children and manual-kineasthetic for blind children.

The method of modelling was implemented by Sękowska (1974) in her research on representation of everyday concepts. A group of 30 blind children between the ages of 5 and 14 with no visual memory, born blind or who lost sight before they were 6 was administered a task of modelling some common objects together with commenting on their models. Sękowska posited that blind children have difficulties presenting objects in motion, in other words, building the understanding of spatial relations. Following Sękowska, the results of the experiment expose that blind children are able to recognise objects and name major constitutes, nevertheless, the quality of such representations depends on a number of factors such as: a curriculum at school, the child's skills and abilities, environment and family background, a range of words a child possesses, the child's individual initiatives and interests.

There is no common agreement whether the lack of sight affects the acquisition of spatial concepts. Klimasiński (1989) found that blind children even in the fourth grade of primary school had problems with spatial concepts usage, particularly, the children exhibited problems with locating one object in reference to another. The key determinant in understanding spatial relations is a well-developed body awareness which acts as a reference around which children organize space. Of particular difficulty is the concept "in front of" because it involves the identification not only of the front of one's body but also the front and back of the objects the child faces (Cratty, Sams 1968).

To sum up this part, some research that has been conducted with a view to investigate concept development in blind children, despite sometimes contradictory results, displays that blindness may impede the development of concept understanding, especially in very early childhood. A blind child is more prone than a sighted child to build concept representations, particularly the representations of concepts that are vision-based, by means of personal experience, thus many of the children's responses are linked to the 
original context in which a given concept was accessed. A sighted child, on the other hand, has much more opportunity to widen the scope of contexts and his or her understanding is more general and context-independent. It may be hence hypothesised that decontextualisation develops slower in blind children as compared to their sighted peers. Later, however, due to the exposure to linguistic clues these conceptual gaps are compensated, here a key role must be given to school where a blind child acquires the knowledge of concepts under the supervision of teachers. A prominent function must also be given to the environment, whether it delivers enough stimulation to propel language and cognitive development. Because family opportunities differ, the awareness of concepts in blind children will also be different. Of interest is the fact that blind children use very effective compensation strategies to arrive at a concept meaning such as analogy and other senses perception. This can also lead to the conviction that blind children have well-developed classification skills, being able to trace minute similarities and differences between various concepts. Because cognitive environments are individual, blind children will pay attention to different features than sighted children do, in the case of blind children it will be other than vision senses such as touch or hearing, while in sighted children sight.

\section{CONCEPTS AS REPRESENTED IN DRAWINGS}

A comprehensive study on drawing by the blind is given by John Kennedy (1993) who in his book "Drawing and the Blind" presents many vital points about the art of drawing and blind people's understanding. His extensive experiments with a vast array of blind children, teenagers and adults prove that the blind can fully understand spatial relations and they do not exhibit any deviations from the norm; they are even able to use metaphors in their drawings. In addition, the development of the drawing skills of blind children is similar to the development of sighted ones. According to Kennedy, touch is able to detect the spatial properties of surfaces just as sight does. The hand of a human being can trace edges, contours, corners etc. in a similar way as vision can, and blind people learn about space by air movements, swirls, whirlpools and other sensations sent from the environment.

The same is contested by Heller's (2002) experiments on the haptic identification of pictures of familiar objects such as animals, body parts etc that show no striking differences between the performance of blind and sighted adults. It stands in opposition to other theories that disregard the role of 
touch claiming that a blind person has problems with combining single touches into one of perception.

Millar's studies (1994) based on the comparison of blind children who have never drawn before, with sighted children, reveal that blind children's drawings do not exhibit any noticeable differences from the pictures produced by sighted children. Blind children, being 10 and upward years of age, draw similar figure scheme: circle for the head, lines or circles for the body, two pairs of lines attached to the middle and bottom etc. Some discrepancies were also observed: the drawings of the sighted children were more elaborate, the sighted children placed the figure in the upright position while the blind placed it anywhere on the page, regardless of orientation, which shows that they did not develop the ability to indicate the figure in relation to the environment. What is more, blind children produced only scribbles taking the form of undifferentiated, dense blots or separate scribbles for body parts. The gap in drawing skills between young and older children was also much more noticeable in blind children than in the case of sighted children. Millar found that blind young children do not use symbols to translate three-dimensional perspective into two dimensional one which takes place in sighted children. That is why blind children's pictures presented scribbles. The use of shapes is a crucial step in drawing development. In blind children, it occurs later which inevitably is caused by the lack of information delivered by vision. Millar confirms that such observations denote that schemes are not acquired through imitation or learning, but there must be an inborn mechanism governing the process of space representation. Blind children build representations in the same way as sighted children do, the only difference being the route of such representations. Blind children rely on haptic rather than visual information.

\section{EXAMPLES}

The study was conducted in the group of blind children who had no previous experience with drawing ${ }^{1}$. The total number of children was 7 children. The age range varied from the youngest child of 8 years of age to the oldest child of 15 years of age. The children were asked to produce drawings based on a given instruction that was as follows: Imagine that you enter a room and there is a table in the middle, there is a mug on the table and a person is standing next to the table. The instrument implemented for

\footnotetext{
1 The drawings were produced by blind children who took part in the programme "English for the Blind" held at the Catholic University of John Paul II in Lublin between 2005-2009. They were collected as part of $\mathrm{PhD}$ research.
} 
blind children was a specially designed raised line drawing kit (a board with a layer of rubber covered by foil). By pressing a ballpoint against the foil, drawings are created.

Drawing number one (example 1), produced by a child age 8 , shows a table from the perspective typical of most blind subjects, from the upper position. The picture thus shows not the whole table but its flat surface as seen from the above vantage point. It is a point of view understandable for the blind child who explores the table by moving hands over the surface.

\section{Example 1}

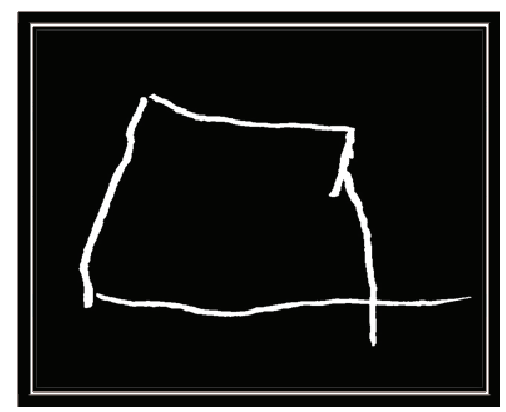

In the next drawing, a child age 7 tries to present more details such as a table (or rather three various tables), a mug on the table, a lamp and a person standing next to the table. A human figure has all basic elements such as a head (although square rather than round), hands and legs as well as the rest of the body. According to the child, a human figure is placed in front of the table (sitting in front and drinking tea). What is interesting is the spatial position of a human figure in reference to the table. A sighted child would use an allocentric perspective (reference to one's body and the object), whereas a blind child prioprioceptive perspective (reference to the object).

\section{Example 2}

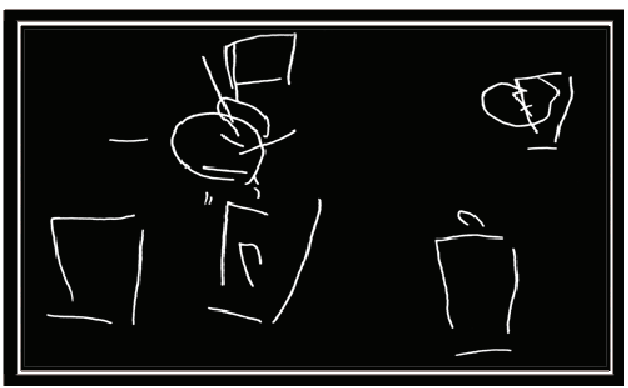


The next drawing, the example number 3, produced by a child age 7 depicts a table from the same point as in the previous drawing, namely the flat surface only is indicated. The image of the mug on the table is presented with an open top that suggests that something like water or juice may be filled.

\section{Example 3}

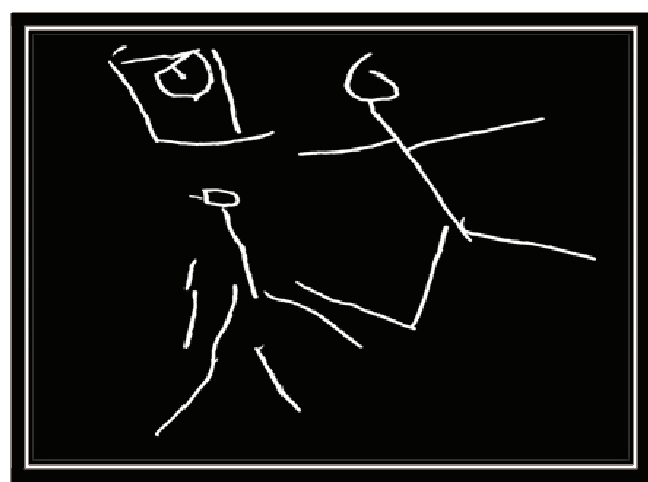

In the example number 4, the table is presented from a different vantage point, as if seen from the front: two legs are indicated. The mug does not resemble the real object and is not a clear representation of such an object existing in reality. The same applies to a person and a cat under the table. One of the problems not directly visible in the drawing is the position of a person in reference to the table. A child, during the activity of drawing, uttered that a man was standing on the left side to the table. This is not a correct interpretation because the man is indicated on the opposite-right side. The figure of a cat under the table is appropriate and very illustrative.

\section{Example 4}

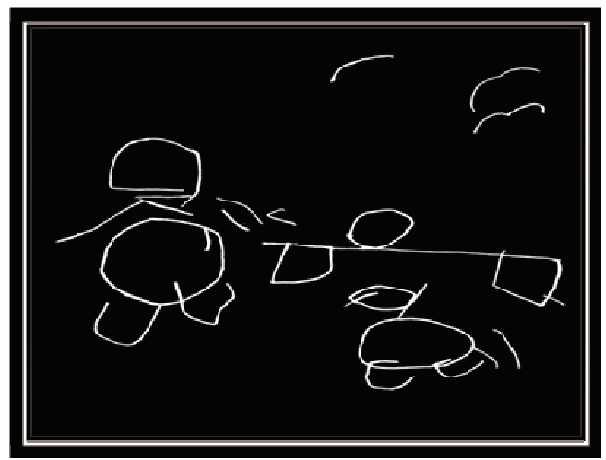


Blind children have a great sense of presenting objects from various positions like the one provided below. The drawing number 5 (a blind child age 12) is an excellent example of the blind child's view of objects. The table has all-important elements like four legs and the flat surface. The child uttered that the same picture applies to a different vantage point: If you go under the table, you see the same table. The child also provided an interesting picture of the mug, the mug is seen with an open lid and a bottom is indicated. Touch explores mainly the elements that are critical to the child, critical in understanding and usage. What is vital in comprehending a mug is its open lid ended with a bottom. Thanks to this property, a liquid may be put inside. It is also a way of detecting what is inside the mug or a glass of any kind; the child, by touching the rim with their fingers, checks whether the container is empty or filled, whether the substance is hot or cold, and what is inside. A sighted person would pay attention to the mug as seen from the front position, to the shape or texture of the mug. Furthermore, the child drew the roundness of the mug, the object being more rounded at the top and less at the bottom depicting a clear shape of the object.

\section{Example 5}

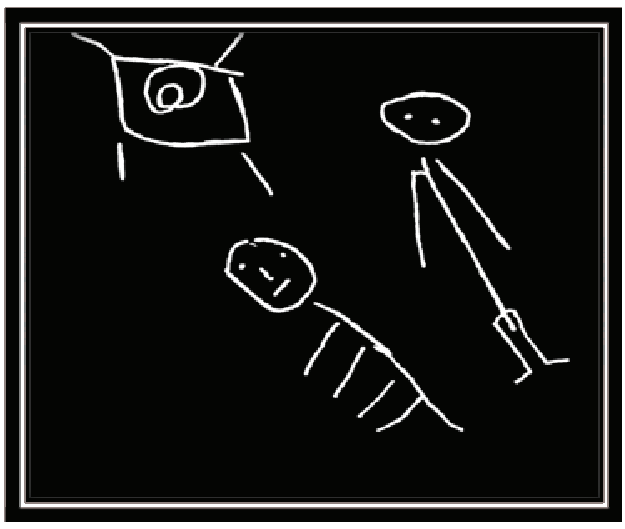

The same strategy was applied to the next picture of the blind child (example 6); here the mug is presented from a different vantage point. But still, the mug has an open lid supplied with a handle. 


\section{Example 6}

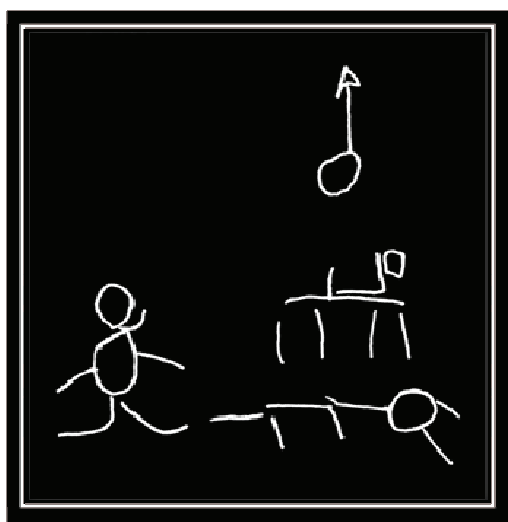

The last picture shows another vantage point; it is the table seen from the side with four legs diverging towards various edges. All legs are indicated and the flat surface is shown by a rectangular form. The mug is not open at the top but has a handle to hold it. The image of a person standing next to the table is very illustrative. Another element indicated in the drawing is a chandelier attached and hanging from the ceiling. The girl went to detail and drew a bulb linked by wire to the exterior of the chandelier. The crucial point to stress here is that the picture was drawn by a 15-year-old girl that suggests improvement in drawing and space representation skills. The blind person develops his or her spatial skills and thus the understanding of concepts is more accurate and correct.

\section{Example 7}

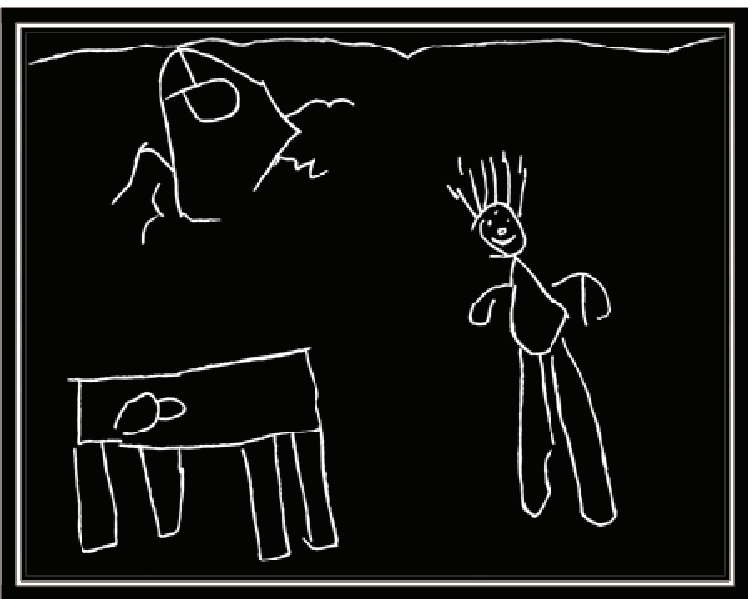




\section{CONCLUSIONS}

The study supports all the theories on drawing skills development in a blind child. It has been found that because of limited access to experience drawing in blind children develops in a slower manner. If given practice in drawing, the children, however, exhibit great skills in producing graphic representations. The understanding of concepts is also proper and does not differ considerably from the understanding of the same concepts by sighted children. Blind children, using other than sight senses, arrive at a correct representation of concepts. Nevertheless, individual differences can be noticed in the perception of concepts with haptic style as dominant on the part of blind children. The study displayed the blind children's problems with spatial concepts understanding. It is not surprising judging at the great difficulty to comprehend spatial relations without the help of sight. Answering the question posed in the title: What has sight got to do with it? We may say that not so much as most of us think. People tend to attach much significance to sight and treat the blind as somehow 'cognitively inferior', whereas it is far from being true.

\section{REFERENCES}

Bussmann, H., Gregory, T., Kazzazi, K., 1996. Routledge dictionary of language and linguistics. London-New York: Routledge.

Cratty, B., Sams, T., 1968. The body-image of blind children. New York: American Foundation for the Blind.

Cutsforth, T., 1932. The unreality of words to the blind. In: Teachers Forum 4, 86-89.

DeMott, R., 1972. Verbalism and affective meaning for blind, severely visually impaired, and normally sighted children. In: New Outlook for the Blind 66 (1), 1-8.

Dokecki, P., 1966. Verbalism and the blind. A critical review of the concept and the literature. In: Exceptional Children 32, 525-530.

Dromi, E., 1999. Early lexical development. In: Barrett, M. (ed.). The development of language. Hove-New York: Psychology Press, 99-126.

Dunlea, A., 1989. Vision and the emergence of meaning. Blind and sighted children's early language. Cambridge: Cambridge University Press.

Gleitman, L., 1990. The structural sources of verb meaning. In: Language Acquisition 1, 3-55.

Heller, M.A., 2002. Tactile picture perception in sighted and blind people. In: Behavioral Brain Research 135, 65-68.

Kennedy, J., 1993., Drawing and the blind. New Haven-London: Yale University Press.

Klimasiński, K., 1989. Organizacja czynności poznawczych przy głębokim defekcie wzroku. Kraków: Wydawnictwo Uniwersytetu Jagiellońskiego.

Landau, B., 1983. Blind children's language is not meaningless. In: Mills, A.E. (ed.). Language acquisition in the blind child: normal and deficient. London: Croom Helm, 62-76.

Landau, B., Gleitman, L., 1985. Language and experience. Evidence from the blind child. Cambridge, Massachusetts-London: Harvard University Press. 
McLinden, M., McCall, S., 2002. Learning through touch. Supporting children with visual impairment and additional difficulties. London: David Fulton Publishers.

Majewski, T., 1983. Psychologia niewidomych i niedowidzacych. Warszawa: Państwowe Wydawnictwo Naukowe.

Margolis, E., Laurence, S., 2006. Concepts. In: Brown, K. (ed.). Encyclopaedia of language and linguistics. Elsevier Science, 817-820.

Millar, S., 1994. Understanding and representing space. Oxford: Oxford University Press.

Perez-Pereira, M., Conti-Ramsden, G., 1999. Language development and social interaction in blind children. Hove-New York: Psychology Press.

Recchia, S., 1997. Play and concept development in infants and young children with severe visual impairments: a constructivist view. In: Journal of Visual Impairment and Blindness, 91, 401-406.

Rosel, J.A., Caballer, P.J., Olivier, J.C., 2005. Verbalism in the narrative language of children who are blind and sighted. In: Journal of Visual Impairment and Blindness, 413-425.

Sękowska, Z., 1974. Ksztatcenie dzieci niewidomych. Warszawa: Polskie Wydawnictwo Naukowe.

Szczechowicz, A., 1976. Swoistość kształtowania się pojęć u dzieci niewidomych. In: Klimasiński, K. (ed.). Procesy poznawcze a defekty sensoryczne. Materiały I Krajowego Sympozjum Psychologii Defektologicznej. Warszawa: Instytut Psychologii, 86-99. 